\title{
Caracterização parcial de um Tymovirus isolado de tomateiros
}

\author{
Isabel Cristina Batista (1,2); Marcelo Eiras ('); Ricardo Harakava (1); Addolorata Colariccio ( ${ }^{1 *}$ ) \\ (') Instituto Biológico (IB), Centro de Pesquisa e Desenvolvimento de Sanidade Vegetal, Avenida Conselheiro Rodrigues Alves, 1252, \\ 04014-002 São Paulo (SP), Brasil. \\ (2) IB, Programa de Pós-graduação em Sanidade, Segurança Alimentar e Ambiental no Agronegócio, São Paulo (SP), Brasil. \\ (*) Autora correspondente: colariccio@biologico.sp.gov.br
}

Recebido: 9/jun./2011; Aceito: 10/fev./2012

\begin{abstract}
Resumo
Um Tymovirus isolado de sementes de tomateiro (Solanum lycopersicum) 'Paronset' com sintomas de necrose, denominado TyToRS08, foi caracterizado quanto ao círculo de hospedeiras, propriedades físico-químicas, sorológicas e moleculares. O vírus foi transmitido mecanicamente a partir de folhas, frutos e sementes infectadas. A gama de hospedeiras incluiu espécies de Amaranthaceae, Chenopodiaceae e Solanaceae, induzindo sintomas local e sistêmicos na maior parte das espécies, exceto para Nicotiana sylvestris, N. tabacum 'Samsun', 'White Burley' e 'Xanthi' que não manifestaram sintomas. Em tomateiros 'Alambra', 'Thomas', 'Diva', 'Romana' e 'Graziela', o vírus induziu sintomas de mosaico e necrose branca. A presença do vírus foi detectada, nas sementes infectadas de todas as cultivares avaliadas, porém não se notou em plântulas após a germinação destas sementes. Foi obtida uma preparação purificada com concentração de 1,04 mg $\mathrm{mL}^{-1}$, empregada na produção de um antissoro policlonal que reagiu em PTA-ELISA com um título de 1/32768. Utilizou-se um par de oligonucleotídeos degenerados, desenhados para anelar na ORF 1 de espécies de Tymovirus, que permitiu a amplificação por RT-PCR de fragmentos com cerca de 700 pb. Após o alinhamento e a análise das sequências, verificou-se que o isolado TyToRS08 possuía valores abaixo de 70\% de identidade com as espécies de Tymovirus, indicando que pode se tratar de uma espécie distinta das descritas no gênero, com potencial epidemiológico, pela sua estabilidade e disseminação por sementes de tomate.
\end{abstract}

Palavras-chave: Tymoviridae, Solanum lycopersicum, transmissão, semente.

\section{Partial characterization of a Tymovirus isolated from tomato}

\begin{abstract}
A Tymovirus isolated from seeds of tomato (Solanum lycopersicum) cv. 'Paronset' with necrosis, named TyToRS08 isolate, was characterized by its host range, physical-chemical, serological and molecular properties. Firstly, it was successfully transmitted by mechanical inoculation by infected seeds, and the host range was restricted to species of Amaranthaceae, Chenopodiaceae and Solanaceae. The symptoms induced by the virus in tomatoes 'Alambra', 'Thomas', 'Diva', 'Romana' and 'Graziela' were mainly mosaic and white necrosis. Nicotiana sylvestris, N. tabacum 'Samsun', 'White Burley' and 'Xanthi' were symptomless. The virus was detected in seeds from five tomato cultivars, but it was not detected in seedlings from these infected seeds. The purified preparation had a high concentration of $1.04 \mathrm{mg} \mathrm{mL}^{-1}$, and the title of the polyclonal antiserum produced, evaluated in PTA-ELISA, was 1/32.768. RT-PCR was performed with degenerated primers directed to the ORF 1 of the tymoviruses, resulting in a DNA fragment of $700 \mathrm{bp}$. The sequence analysis revealed that TyToRSO8 isolate presents higher values of percentage of identity with other species of Tymovirus. The highest identity values were under $70 \%$, indicating that TyToRS08 should be a distinct species of the genus Tymovirus, with great epidemiological importance due to its high stability and potential to be spread by tomato seeds.
\end{abstract}

Key words: Tymoviridae, Solanum lycopersicum, transmission, seed.

\section{INTRODUÇÃO}

O tomateiro (Solanum lycopersicum) é, atualmente, o segundo produto olerícola mais cultivado no mundo, com o Brasil ocupando o nono lugar na produção mundial. A produção nacional de tomate, em 2009, ultrapassou os quatro milhóes de toneladas, concentrando as maiores produçôes nos Estados de Goiás, São Paulo, Minas Gerais e Paraná (IBGE, 2010).
As viroses constituem um dos principais entraves para a produçáo de tomate, causando quebras de produção, devido às dificuldades de controle e à perda da qualidade dos frutos. No Brasil, dentre os vírus já relatados em tomateiros verificaram-se as espécies pertencentes aos gêneros: Cucumovirus, Begomovirus, Polerovirus, Potyvirus, Tobamovirus, Tospovirus e Tymovirus (Blancard, 1996; Ribeiro et al., 1996; Kurozawa e Pavan, 1997; Colariccio, 2004). 
A família Tymoviridae engloba os gêneros Marafivirus, Maculavirus e Tymovirus. As espécies pertencentes ao gênero Tymovirus possuem partículas isométricas cheias e vazias, com $30 \mathrm{~nm}$ de diâmetro e induzem à formação de vesículas com membrana dupla na periferia dos cloroplastos. Possuem RNA de fita simples náo segmentado, com tamanho do genoma que pode variar de 6,0 a $6,7 \mathrm{~Kb}$, contendo três fases abertas de leitura $(\mathrm{ORF})$ e regiôes não traduzidas, no terminal 5' (-m7GpppG-cap) e uma estrutura secundária no terminal 3' que mimetiza um RNA transportador com um anticódon do aminoácido valina. Existem vinte e três espécies definitivas classificadas no gênero Tymovirus, e duas espécies tentativas (Haenni e Dreher, 2008). Os vírus do gênero Tymovirus têm sido descritos em espécies botânicas importantes para a agricultura, pertencentes principalmente às famílias Cucurbitaceae, Brassicaceae e Solanaceae (PAGán et al., 2010). Eles possuem distribuição mundial, amplo círculo de hospedeiras, ocorrem em alta concentraçáo, nas plantas infectadas e podem ser transmitidos mecanicamente, por besouros crisomelídeos e, eventualmente, por sementes (Gibbs e Harrison, 1973; Martelli et al., 2002; Dreher et al., 2005; Colariccio et al., 2008).

$\mathrm{O}$ primeiro relato da ocorrência de um tymovírus, no Brasil, foi feito por Kitajima (1968) em berinjela. Posteriormente, ocorrências de outros tymovírus foram relatadas em maracujazeiro (Crestani et al., 1986), fumo (Ribeiro et al., 1996), petúnia (AleXandre et al., 2000), peperomia (RIvas et al., 2003) e tomateiros Colariccio et al., 2008). Em tomateiro, o relato da primeira ocorrência de Tymovirus foi feito por Chagas et al. (1975), em Itaquaquecetuba (SP), denominando o isolado de "Vírus da Necrose Branca do Tomateiro" (VNBT), o qual foi posteriormente identificado como Eggplant mosaic virus (EMV). Nesses trabalhos, empregaram-se técnicas de identificação biológicas, de microscopia eletrônica, sorológicas e moleculares. Em 2008, nova ocorrência de Tymovirus, em tomateiros, foi registrada a partir de sementes com sintomas de necrose, oriundas de frutos pouco desenvolvidos e com aspermia, provenientes do Rio Grande do Sul, sendo o isolado denominado TyToRS08. A identificação foi realizada por técnicas biológicas, sorológicas e microscopia eletrônica de transmissão (Colariccio et al., 2008)

Este trabalho teve por objetivo caracterizar e identificar o isolado TyToRS08 pelo círculo de hospedeiras, transmissão pelas sementes, purificação do vírus, produção de antissoro policlonal, análises sorológicas e moleculares.

\section{MATERIAL E MÉTODOS}

\section{Fonte e manutenção do vírus}

Amostras de frutos de tomateiros (Solanum lycopersicum) 'Paronset', provenientes de Caxias do Sul (RS), infectados com mosaico, manchas brancas e aspermia, mantidas na Coleção de Fitovírus Karl Silberschmidt (CoFiKS) a $-20{ }^{\circ} \mathrm{C}$, após a desidratação em $\mathrm{CaCl}_{2}$, foram utilizados como fonte de inoculo, de tomateiros 'Alambra', empregados no presente trabalho.

\section{Círculo de hospedeiras}

Para a determinação do círculo de hospedeiras, foram submetidas à inoculaçáo dez plantas de cada espécie: Arachis hypogaea (Fabaceae), Brassica oleracea (Brassicaceae), Chenopodium amaranticolor, C. murale e C. quinoa (Amaranthaceae), Cucurbita pepo e C. moschata (Cucurbitaceae), Capsicum annuum 'Ikeda', Datura metel, D. stramonium, Gomphrena globosa (Amaranthaceae), Lactuca sativa (Asteraceae), Nicotiana tabacum 'White Burley', 'Samsun' e 'Xanthi', N. glutinosa, N. debneyi, $N$. megalosiphon, $N$. rustica, $N$. sylvestris, $N$. clevelandii, Physalis angulata, Solanum lycopersicum 'Diva', 'Alambra', 'Graziella', 'Romana' e 'Thomas', S. melongena 'Santa Genebra', 'Japonesa', 'Embu', 'Napoli' e 'Porta Enxerto', $S$. nigrum e $S$. gilo (Solanaceae). As plantas foram inoculadas mecanicamente com extrato bruto de folhas de tomateiro 'Alambra' infectado pelo isolado TyToRS08, obtido pela trituração das folhas com solução de sulfito de sódio $0,5 \%, \mathrm{pH} 6,0$ na proporçấo de $1: 5\left(\mathrm{~g} \mathrm{~mL}^{-1}\right)$, adicionando-se "carborundum" (400 mesh). Foram submetidas à inoculaçẫo duas plantas de cada espécie com o mesmo procedimento adotado para a transmissão do vírus como controle. Após a inoculação, as plantas foram mantidas em casa de vegetação para observação dos sintomas e para a recuperação do vírus das plantas com e sem sintomas, por inoculação mecânica em $C$. amaranticolor e PTA-ELISA. O ensaio foi repetido quatro vezes durante fevereiro, março, abril e julho de 2010.

\section{Purificação do vírus}

O vírus foi purificado, empregando-se folhas infectadas de tomateiro 'Alambra', pelo método descrito por CHAGAS et al. (1975), com modificaçôes, adicionando-se polietilenoglicol (PEG) 6000 (8\%) e cloreto de sódio (4\%) ao sobrenadante por duas vezes. A preparação semipurificada foi submetida ao gradiente de densidade linear de sacarose (0-50\%) e ultracentrifugada a $65.000 \mathrm{~g}$, por uma hora, em rotor TH (Sorvall). As bandas resultantes foram coletadas e submetidas à nova ultracentrifugação nas mesmas condiçôes anteriores. No fim do processo, foi realizada leitura da preparaçáo purificada em espectrofotômetro UV-160A (Shimadzu) nos comprimentos de onda de 220 a $300 \mathrm{~nm}$, para obtenção da curva de nucleoproteína e cálculo da concentração. A avaliação da presença das partículas de vírus, da preservação da infectividade, e da 
integridade das partículas, nas preparaçóes purificadas, foi feita pela visualização das partículas em contraste negativo em microscópio eletrônico de transmissão e pela inoculação mecânica em C. amaranticolor.

\section{Produção de antissoro policlonal}

A produção do antissoro policlonal para o isolado TyToRS08, foi feita pela imunização de camundongos da linhagem Balb/c pela via intramuscular, com $0,2 \mathrm{~mL}$ da preparaçấo purificada do isolado TyToRS08, na concentração de $1 \mathrm{mg} \mathrm{mL}^{-1}$, aplicando-se duas injeçôes, com intervalo de 15 dias entre elas, sendo a primeira injeção em adjuvante completo de Freund e a segunda em adjuvante incompleto de Freund. Após 15 dias da segunda imunização, foi realizada uma sangria e a separação do antissoro, titulado por PTA-ELISA e armazenado a $-20^{\circ} \mathrm{C}$. Na titulaçáo foram empregadas diluiçóes do antissoro de 1:512 até 1:32.768, avaliadas com o extrato bruto de $S$. lycopersicum 'Alambra' infectadas com o isolado TyToRS08, homogeneizadas em tampão carbonato de sódio $\mathrm{pH} 9,6$, na proporção de $1: 5\left(\mathrm{~g} \mathrm{~mL}^{-1}\right)$ e $1: 10\left(\mathrm{~g} \mathrm{~mL}^{-1}\right)$, e amostras da preparação semipurificada diluída na proporçáo de 1:80 (v/v) empregando-se, como controle negativo, extrato bruto de tomateiro sadio, na proporção de $1: 5\left(\mathrm{~g} \mathrm{~mL}^{-1}\right)$ e 1:10 $\left(\mathrm{g} \mathrm{mL}^{-1}\right)$. A leitura da absorbância das amostras foi realizada em leitor de ELISA (modelo 3550-UV, BioRad) a $405 \mathrm{~nm}$.

\section{Detecção do vírus em sementes e plântulas por PTA-ELISA}

Para a detecção do vírus nas sementes de tomateiro, foram submetidas à inoculaçáo com o isolado TyToRS08, tomateiros das cultivares Alambra, Diva, Graziella, Romana e Thomas, posteriormente, transplantadas para solo, em uma estufa de cultivo protegido, localizada em Bragança Paulista (SP). No fim do ciclo, coletaram-se os frutos com e sem sintomas de todas as plantas infectadas e retiraram-se todas as sementes, com sintomas de necrose e sem sintomas. Para verificar a porcentagem de sementes infectadas, 72 sementes de cada cultivar divididas em dois lotes de 36 sementes, um de sementes lavadas e outro de sementes não lavadas (solução de hipoclorito de sódio a 4\%), foram avaliadas, individualmente, em PTA-ELISA, empregando-se o extrato-bruto das sementes diluído 1:10 (v:v) e o antissoro TyToRS08 na diluição 1:3000 (v:v).

Para avaliar a presença do vírus em sementes com e sem necrose foi empregada uma amostra de cem sementes divididas em dois lotes, um com 50 sementes com necrose e outro com 50 sementes sem necrose. Cada lote de 50 sementes foi subdividido em dois lotes de 25 sementes, um de sementes lavadas e outro de sementes não lavadas, cada lote avaliado em PTA-ELISA, empregando-se extrato-bruto de sementes diluído 1:10 (v:v), e o antissoro-TyToRS08 na diluição 1:3000 (v:v).

A avaliação da presença do vírus nas plântulas foi realizada após a germinação das sementes em caixas de acrílico $\left(\right.$ Gerbox $\left.^{\circledR}\right)$ forradas com papel de germinação e mantidas em BOD a $25^{\circ} \mathrm{C}$, empregando-se uma amostra de cem sementes, de cada cultivar, dividida em dois lotes, um com 50 sementes com necrose e outro com 50 sementes sem necrose. Cada lote de 50 sementes foi subdividido em dois lotes de 25 sementes, um de sementes lavadas e outro de sementes não lavadas. As plântulas foram avaliadas por PTA-ELISA, 20 dias após a germinação, no estádio de desenvolvimento de folhas cotiledonares, empregando-se extrato-bruto de plântulas diluído 1:10 (v:v), e o antissoro-TyToRS08 na diluição 1:3000 (v:v).

\section{Detecção da proteína capsidal do vírus por Western-blot}

Folhas de tomateiro 'Alambra' e de $N$. debneyi infectadas pelo isolado TyToRS08, e alíquotas da preparação purificada do vírus na diluição 1:10 (v:v), foram submetidas a SDS-PAGE e Western-blot. As amostras foram desnaturadas em tampão de desnaturação (Tris $\mathrm{HCl}, \mathrm{pH}$ 6,8, glicerol, SDS $10 \%)$ na proporção de $1: 5\left(\mathrm{mg} \mathrm{mL}^{-1}\right)$, aquecidas a $95{ }^{\circ} \mathrm{C}$ por 5 minutos. Em seguida, alíquotas de $15 \mu \mathrm{L}$ de cada amostra foram aplicadas nos géis e submetidas à eletroforese a 200 volts por 45 minutos. Após a eletroforese, os géis de poliacrilamida foram transferidos para membrana de nitrocelulose por 30 minutos a 23 A e 15 $\mathrm{V}$ com auxílio de aparato de transferência (Trans-blot $\mathrm{SD}^{\circledR}$, Bio-Rad). Após secagem em estufa por 10 minutos, a membrana foi colocada em contato com a solução bloqueadora $(0,2 \%$ de leite desnatado diluído em tampão TTBS [Tris-buffered saline (TBS) acrescido de Tween] por 30 minutos. Após lavagem em TTBS, acrescentou-se o antissoro contra TyToRS08 (AS-TyToRS08) 1:2000 (v:v), incubando-se por 1 hora a $37^{\circ} \mathrm{C}$. A revelação da membrana foi feita em soluçáo de BCIP e NBT. Como controle negativo empregaram-se folhas de tomateiro 'Alambra' sadias.

\section{Extração de RNA total, RT-PCR e sequenciamento}

Para a extração do RNA total, empregou-se o procedimento descrito por CHOMCZYnski e SACCHI (1987). Utilizaram-se fragmentos foliares de tomateiro 'Alambra' infectado pelo TyToRS08 e como controle positivo foram empregados os isolados de Tymovirus denominados VNBT e EMV-PEP pertencentes à Coleção de fitovírus 'Karl Martin Silberschmidt' (CoFiKS), e como controle 
negativo, fragmentos foliares de tomateiro 'Alambra' sadios. Para a síntese das moléculas de DNA complementar e a amplificação dos motivos III e IV da metiltransferase e helicase empregou-se o kit Acess Quick (Promega) em one-step, de acordo com as instruções do fabricante, acrescentando-se $1 \mathrm{~mL}$ de RNA, $10 \mathrm{~mL}$ de tampão, 0,4 $\mathrm{mL}$ de oligonucleotídeos degenerados MTR1 (5'TTCATGCAYGAYGCYMTSATGT3') e MTR2 (5'TCCCAVGCNBHBCVRGTGACCCA3') empregando-se as condiçôes descritas por SABANADZOVic et al. (2000). Foram empregados também oligonucleotídeos específicos [EMV-CPs (5'AGATCAATGGAAGACACAGC3') e EMV-CPc (5'GAGAGAGTTAATTGGCTTGGA 3')], desenhados com base no alinhamento de sequências de nucleotídeos da CP de isolados de EMV depositados no GenBank.

As sequências obtidas dos motivos III e IV da metiltransferase e helicase foram comparadas com as sequências existentes no GenBank por meio do programa BLAST do $\mathrm{NCBI}$, e alinhadas manualmente com o programa Se-Al, versão 1.0 alpha 1 . A determinação da identidade das sequências foi realizada com o programa PAUP $4.0 \mathrm{~b} 10$ para Macintosh (SwOFFord, 2002). As construções filogenéticas foram feitas utilizando as sequências de aminoácidos. As árvores foram visualizadas com o programa MEGA 4.0 (TAmura et al., 2007).

\section{RESULTADOS E DISCUSSÃO}

Dentre as hospedeiras avaliadas, uma ampla gama manifestou sintomas para o isolado TyToRS08. Em S. lycopersicum 'Alambra', o TyToRS08 induziu clareamento de nervuras, faixa das nervuras, mosqueado e, especialmente, o sintoma de necrose branca, sintoma típico de tymovírus em tomateiro (CHAGAs et al., 1975; Gracia et al., 1998). Os mesmos sintomas foram observados em tomateiros das cultivares Diva, Graziella, Romana e Thomas. O TyToRS08 induziu lesôes locais cloróticas em Chenopodium amaranticolor, C. murale, C. quinoa, Datura stramonium e Gomphrena globosa, sintomas que evoluíram para mosaico sistêmico e necrose branca no limbo foliar. Em Lactuca sativa foram observados clareamento de nervuras e bolhosidade, e Nicotiana clevelandii, Nicotiana debneyi, Nicotiana glutinosa, Nicotiana megalosiphon, Nicotiana rustica, Solanum gilo, Solanum melongena 'Santa Genebra', 'Japonesa', 'Embu', 'Napoli' e 'Porta Enxerto' e Solanum nigrum reagiram com sintomas sistêmicos de mosaico. As hospedeiras Cucurbita pepo, Cucurbita moschata, Brassica oleracea, Nicotiana sylvestris, N. tabacum 'Samsun', 'White Burley' e 'Xanthi' não manifestaram sintomas e $\mathrm{o}$ vírus não pôde ser delas recuperado (Tabela 1). Pelos resultados observados, das 34 espécies submetidas à inoculação apenas 8 não foram suscetíveis ao TyToRS08, confirmando que os Tymovirus se transmitem com facilidade, por inoculação mecânica, para um grande número de hospedeiras em diferentes famílias, semelhantes àqueles descritos na literatura para o EMV (Gibbs e Harrison, 1973).

Pela comparação do círculo de hospedeiras do isolado TyToRS08 com o isolado do EMV de tabaco (EMV-TAB), estudado por Ribeiro et al. (1996), e do isolado de EMV de tomateiro (EMV-TOM), estudado por Gracia et al. (1998) na Argentina, verificou-se que existem diferenças na suscetibilidade das plantas hospedeiras, pois N. tabacum 'White Burley', 'Xanthi' e 'Samsun', reagiram com sintomas sistêmicos aos dois isolados, diferenciando-se do TyToRS08 que não induziu sintomas nestas hospedeiras, assim como o VNBT (Chagas et al., 1975) e o EMV isolado de Peperomia obtusifolia, EMV-PEP (RIVAs et al., 2003). $\mathrm{O}$ isolado TyToRS08 induziu sintomas de mosaico sistêmico em G. globosa, assim como os isolados VNBT e EMV-TOM. EMV-TAB e EMV-PEP não induziram sintomas nessa hospedeira. Com relação às demais hospedeiras, todos os isolados induziram sintomas semelhantes, verificando-se que o teste biológico possibilita diferenciar estirpes de vírus.

Inclusôes citoplasmáticas típicas de Tymovirus foram detectadas em plantas de Datura stramonium infectadas pelo isolado TyToRS08. Foi possível observar ao microscópio de luz aglomerados de cloroplastos situados próximos ao núcleo das células (dados náo apresentados). As alteraçóes causadas nos cloroplastos atuam na perda da capacidade fotossintética e estão relacionadas aos sintomas de mosaico e perda de coloração das folhas. BarRadas e Colariccio (1986) estudaram a indução de inclusōes em quatro isolados de EMV, concluindo que, em todos os casos, foi possível detectar inclusóes amorfas constituídas de um aglomerado de cloroplastos degenerados, nas proximidades do núcleo.

Após centrifugação em gradiente de sacarose de 0 a $50 \%$ da preparação semipurificada do vírus, houve a formação de duas bandas opalescentes, a 2,0 e 2,8 cm de altura do menisco, sendo a primeira banda correspondente à fração $\mathrm{T}\left(T_{o p}\right)$, constituída de partículas vazias e a segunda, correspondente à fração $\mathrm{B}$ (Bottom), de partículas cheias. A concentraçáo do vírus foi de $1,04 \mathrm{mg} \mathrm{mL}^{-1}$ de partículas isométricas cheias e vazias com ca. de $30 \mathrm{~nm}$ de diâmetro, típicas de tymovírus (Figura 1).

O antissoro produzido (AS-TyToRS08) a partir dessa preparação reagiu positivamente até a diluição 1:32768, entretanto as melhores leituras para detectar o vírus em PTA-ELISA foram obtidas nas diluiçóes 1:3000 e 1:4096.

A massa molecular da proteína capsidal do isolado TyToRS08 foi detectada por Western-blot utilizando o antissoro AS-TyToRS08 na diluição 1:2000, sendo a massa molecular estimada em cerca de $20 \mathrm{kDa}$ (dados não apresentados). Resultados semelhantes foram obtidos por Chagas et al. (1975) para o VNBT, por Ribeiro et al. 
(1996) para o isolado EMV-TAB e por Rivas et al. (2003) para o isolado EMV-PEP, que obtiveram o mesmo valor de $20 \mathrm{kDa}$, para a proteína do capsídeo viral destes isolados, em SDS-PAGE.

Os frutos produzidos no campo experimental por 'Alambra', 'Thomas', 'Diva', 'Romana' e 'Graziela' manifestaram sintomas foliares de necrose branca (Figura 2a), deformação foliar e reduçâo de crescimento, frutos com aspermia (Figura 2b), sendo observados sintomas mais drásticos na cultivar 'Romana', a mais suscetível ao vírus, produzindo frutos menores, com sintomas de esbranquiçamento na epiderme (Figura 2c) e frutos com necrose nas sementes (Figura 2d).

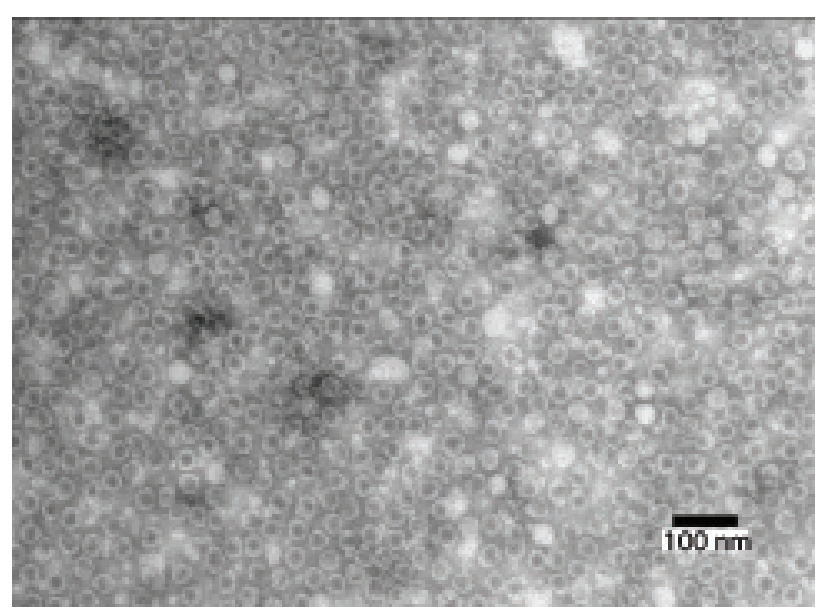

Figura 1. Micrografia eletrônica da preparaçáo purificada do TyToRS08, na diluição de 1:10 em tampão fosfato de sódio 0,1 molar, pH 7,0, na qual são visualizadas partículas isométricas, cheias e vazias, de cerca de $30 \mathrm{~nm}$.

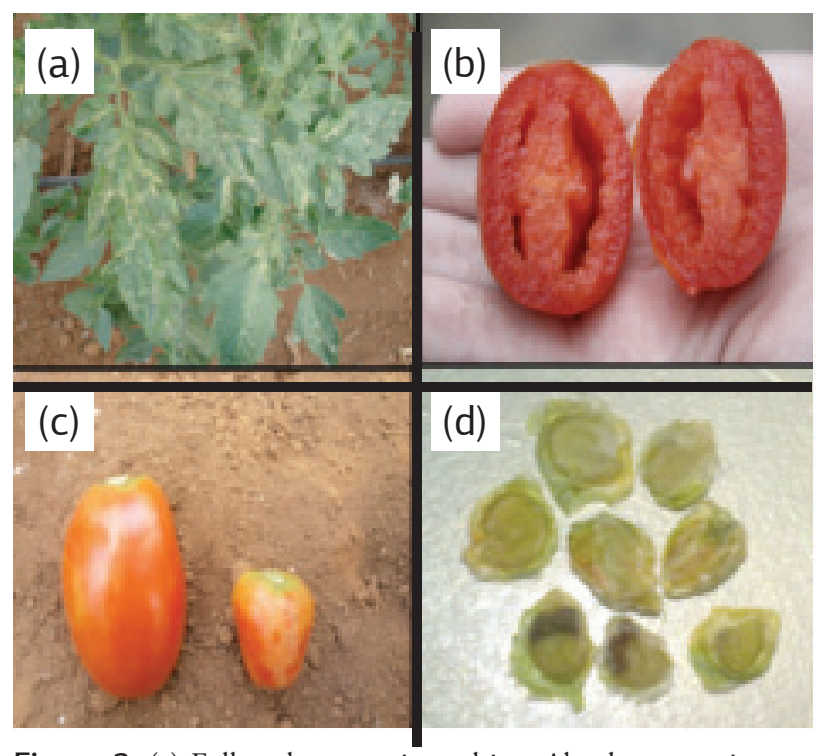

Figura 2. (a) Folhas de tomateiro cultivar Alambra com sintoma de mosaico e necrose branca induzidos pelo isolado TyToRS08; (b) Aspermia em tomate cultivar Romana; (c) Tomate cultivar Romana sem sintoma (esquerda) e com sintoma de mancha branca (direita); (d) sementes de tomateiro cultivar Alambra com necrose.
O número total de sementes produzidas por cultivar foi de 3.221 em 'Alambra', sendo 396 com necrose; 5.433 em 'Thomas', sendo 833 com necrose; 5.250 em 'Diva' sendo 400 com necrose; 1675 em 'Romana', sendo 100 com necrose e 2908 em 'Graziela', sendo 333 com necrose. A cultivar Thomas foi a que mais produziu sementes com necrose, totalizando $15 \%$, e a Romana, a que menos produziu sementes com necrose, totalizando 6\%. Este resultado para a cultivar Romana pode ser atribuido à maior produção de frutos com aspermia, acarretando baixa produção de sementes (Tabela 2).

O TyToRS08 foi detectado nas sementes lavadas e não lavadas, de todas as cultivares de tomateiro, porém

Tabela 1. Círculo de hospedeiras e sintomas induzidos pelo isolado TyToRS08

\begin{tabular}{|c|c|c|}
\hline Família e espécie botânica & $\begin{array}{l}\text { Sintoma } \\
\text { local }\end{array}$ & $\begin{array}{l}\text { Sintoma } \\
\text { sistêmico }\end{array}$ \\
\hline \multicolumn{3}{|l|}{ Amaranthaceae } \\
\hline Gomphrena globosa & LC & M \\
\hline \multicolumn{3}{|l|}{ Asteraceae } \\
\hline Lactuca sativa & - & $\mathrm{CN}, \mathrm{B}$ \\
\hline \multicolumn{3}{|l|}{ Brassicaceae } \\
\hline Brassica oleraceae & - & - \\
\hline \multicolumn{3}{|l|}{ Chenopodiaceae } \\
\hline Chenopodium amaranticolor & LC, LN & M \\
\hline C. murale & LC, LN & M \\
\hline C. quinoa & LC, LN & $M, A M$ \\
\hline \multicolumn{3}{|l|}{ Cucurbitaceae } \\
\hline Cucurbita moschata & - & - \\
\hline Cucurbita pepo & - & - \\
\hline \multicolumn{3}{|l|}{ Fabaceae } \\
\hline Arachis hypogea & - & - \\
\hline \multicolumn{3}{|l|}{ Solanaceae } \\
\hline Capsicum annuum 'Ikeda' & - & DF, B \\
\hline Datura metel & LC, LN, LCA & CN, M, DF \\
\hline D. stramonium & LC, LN & $\mathrm{M}, \mathrm{CN}, \mathrm{B}, \mathrm{DF}$ \\
\hline Nicotiana clevelandii & LC & M \\
\hline N. debneyi & LC & M \\
\hline N. glutinosa & LC, LN & M \\
\hline N. megalosiphon & LC & DF, M \\
\hline N. rustica & LC, LN & AM \\
\hline N. sylvestris & - & - \\
\hline N. tabacum 'Samsun' & - & - \\
\hline N. tabacum 'White Burley’ & - & - \\
\hline N. tabacum 'Xanthi' & - & - \\
\hline Physalis angulata & - & - \\
\hline Solanum gilo & LC, LN & $\mathrm{AM}, \mathrm{B}, \mathrm{DF}, \mathrm{CN}$ \\
\hline $\begin{array}{l}\text { S. lycopersicum 'Alambra', 'Diva', } \\
\text { 'Graziela', 'Romana', 'Thomas' }\end{array}$ & LC & $\mathrm{CN}, \mathrm{FN}, \mathrm{MO}, \mathrm{M}$ \\
\hline $\begin{array}{l}\text { S. melongena 'Santa Genebra', } \\
\text { 'Japonesa', 'Embu', 'Napoli', } \\
\text { 'Porta Enxerto' }\end{array}$ & LC & $\begin{array}{c}\mathrm{M}, \mathrm{B}, \mathrm{FN}, \mathrm{AM}, \\
\mathrm{NB}\end{array}$ \\
\hline S. nigrum & LC & $\mathrm{CN}, \mathrm{FN}, \mathrm{DF}$ \\
\hline
\end{tabular}

Representação dos sintomas: (-) ausência de sintomas; AM: amarelecimento; $\mathrm{B}$ : bolhosidade; CL: clorose; CN: clareamento de nervuras; DF: deformação foliar; FN: faixa de nervuras; LC: lesão local clorótica; LCA: lesão local clorótica com contorno anelar; LN: lesão local necrótica; $\mathrm{MC}$ : mancha clorótica; $\mathrm{M}$ : mosaico; $\mathrm{MB}$ : mosaico com bolhas; MO: mosqueado; MF: mosaico em faixas; NB: necrose branca. 
a maior porcentagem de sementes infectadas ocorreu quando estas não foram previamente lavadas (Tabela 3). Dentre as cultivares avaliadas, a maior porcentagem de sementes infectadas ocorreu em Thomas $(61,1 \%$ em sementes lavadas e $91,6 \%$ em sementes não lavadas) (Tabela 3). $\mathrm{O}$ vírus também foi detectado nas sementes previamente lavadas de todas as cultivares, porém em menor porcentagem (Tabela 3), possivelmente pelo fato de o vírus estar presente no tegumento da semente e/ou em sua mucilagem; é possível também de o vírus não atingir internamente a semente, devido à necrose que pode formar uma barreira para sua disseminação nas células embrionárias ou por estar em uma camada interna da semente.

O TyToRS08 foi detectado em todas as sementes com necrose quando não lavadas. Entretanto, nas sementes com necrose lavadas o vírus só foi detectado nas cultivares Alambra, Diva e Romana (Tabela 3). Nas sementes sem necrose não lavadas, o vírus foi detectado em todas as sementes de todas as cultivares. Entretanto, nas sementes sem necrose lavadas, o vírus só foi detectado em 'Romana', possivelmente pelo fato de existir uma alta taxa de infecção das sementes nesta cultivar e da possibilidade do vírus ter atingido internamente a semente.

O isolado TyToRS08 não foi detectado em plântulas após a germinaçấo das sementes com necrose e sem necrose (Tabela 4), indicando que apesar das sementes estarem infectadas e manifestarem sintomas, $\mathrm{o}$ vírus não foi transmitido para as folhas cotiledonares. Menrotra e AgGarwal (2003) relataram que sementes infectadas podem originar plântulas, nas quais o vírus não pode ser detectado, devido ao fato de náo atingir as células do embriāo. Resultado semelhante foi obtido por SARAIVA et al. (2006), em que os autores constataram a ausência do Papaya lethal yellowing virus (PLYV) em plântulas germinadas a partir de sementes infectadas, porém constataram a presença do vírus nas sementes infectadas, concluindo que o vírus não foi transmitido pelas sementes de forma embrionária. Estudos sobre a evolução da transmissão dos vírus por sementes realizados por Assis Filho e SHERWOOd (2000) com o Turnip yellow mosaic virus (TYMV), Tymovirus, e Tomato mosaic virus (ToMV), Tobamovirus, em Arabidopsis thaliana, demonstraram que

Tabela 2. Número e porcentagem de frutos e sementes com e sem necrose produzidos por tomateiros experimentalmente infectados pelo isolado TyToRS08, em campo experimental de Bragança Paulista

\begin{tabular}{lcccrrr} 
Cultivares & $\begin{array}{c}\text { Número de frutos com sintoma } \\
\text { de mancha branca/total }\end{array}$ & $\%$ & $\begin{array}{c}\text { Número de frutos com } \\
\text { aspermia/total }\end{array}$ & $\%$ & $\begin{array}{c}\text { Número de sementes com } \\
\text { necrose/total }\end{array}$ & $\begin{array}{c}\text { (1) } \\
\text { nes }\end{array}$ \\
\hline Alambra & $29 / 68$ & 19,7 & $7 / 68$ & 10,2 & $396 / 3221$ & 12,0 \\
Thomas & $10 / 67$ & 6,7 & $14 / 67$ & 20,8 & $833 / 5433$ & 15,0 \\
\hline Diva & $2 / 73$ & 1,4 & $1 / 73$ & 1,3 & $400 / 5250$ & 7,6 \\
\hline Romana & $75 / 114$ & 85,5 & $56 / 114$ & 49,1 & $100 / 1675$ & 6,0 \\
\hline Graziela & $23 / 53$ & 12,2 & $14 / 53$ & 26,4 & $333 / 2908$ & 11,4 \\
\hline
\end{tabular}

(1) Número total de sementes com necrose obtidas de frutos com e sem sintomas.

Tabela 3. Número e porcentagem de sementes lavadas e não lavadas, avaliadas, provenientes de tomateiros experimentalmente infectados pelo isolado TyToRS08

\begin{tabular}{lcccc} 
Cultivares & \multicolumn{2}{c}{ Sementes lavadas } & \multicolumn{2}{c}{ Sementes não lavadas } \\
\cline { 2 - 5 } & $\begin{array}{c}\text { Número de sementes } \\
\text { infectadas/total (1) }\end{array}$ & $\begin{array}{c}\text { Sementes infectadas } \\
(\%)\end{array}$ & $\begin{array}{c}\text { Número de sementes } \\
\text { infectadas/total (1) }\end{array}$ & $\begin{array}{c}\text { Sementes infectadas } \\
(\%)\end{array}$ \\
\hline Alambra & $16 / 36$ & 44,4 & $30 / 36$ & 83,3 \\
\hline Diva & $3 / 36$ & 8,3 & $14 / 36$ & 38,8 \\
\hline Romana & $13 / 36$ & 36,1 & $28 / 36$ & 77,7 \\
\hline Graziela & $1 / 36$ & 2,7 & $18 / 36$ & 50,0 \\
\hline Thomas & $22 / 36$ & 61,1 & $33 / 36$ & 91,6 \\
\hline
\end{tabular}

(1) Número total de sementes avaliadas para cada cultivar.

Tabela 4. Detecção do isolado TyToRS08 em sementes com e sem necrose e em plântulas de tomateiro por PTA-ELISA com antissoro policlonal específico contra o TyToRS08

\begin{tabular}{|c|c|c|c|c|c|c|c|c|}
\hline \multirow{3}{*}{ Cultivar } & \multicolumn{4}{|c|}{ Sementes } & \multicolumn{4}{|c|}{ Plântulas germinadas } \\
\hline & \multicolumn{2}{|c|}{ Sementes sem necrose } & \multicolumn{2}{|c|}{ Sementes com necrose } & \multicolumn{2}{|c|}{ Sementes sem necrose } & \multicolumn{2}{|c|}{ Sementes com necrose } \\
\hline & Lavada & Não lavada & Lavada & Não lavada & Lavada & Não lavada & Lavada & Não lavada \\
\hline Alambra & - & + & + & + & - & - & - & - \\
\hline Thomas & - & + & - & + & - & - & - & - \\
\hline Diva & - & + & + & + & - & - & - & - \\
\hline Graziela & - & + & - & + & - & - & - & - \\
\hline Romana & + & + & + & + & - & - & - & - \\
\hline
\end{tabular}


o TYMV era transmitido por semente de forma embrionária, pois era detectado em plântulas germinadas a partir de sementes infectadas. Porém, o mesmo não ocorria para o ToMV, que não era detectado em plântulas germinadas de sementes infectadas, mas era detectado no envoltório dessas sementes. Os resultados observados neste trabalho indicam que o isolado TyToRS08 foi detectado em sementes de tomateiros, tanto na mucilagem quanto no

Tabela 5. Valores de identidade (em porcentagem) de nucleotídeos (nt) e aminoácidos deduzidos (aa) dos motivos III e IV da metiltransferase e helicase do isolado TyToRS08 e VNBT, caracterizados neste trabalho, comparados com outras espécies de Tymovirus depositadas no GenBank

\begin{tabular}{|c|c|c|c|}
\hline Espécies de Tymovirus (acrônímia) & Código de acesso no GenBank & $\begin{array}{c}\text { TyToRS08 } \\
\text { nt/aa }\end{array}$ & $\begin{array}{l}\text { VNBT } \\
\text { nt/aa }\end{array}$ \\
\hline Eggplant mosaic virus (EMV) & J04374 & $68 / 76$ & 70/76 \\
\hline Chayote mosaic virus (ChMV) & AF195000 & 70/71 & $69 / 70$ \\
\hline Physalis mottle virus (PhyMV) & Y16104 & $69 / 67$ & $66 / 65$ \\
\hline Scrophularia mottle virus (SrMV) & AY751777 & $63 / 65$ & $64 / 64$ \\
\hline Okra mosaic virus (OkMV) & EF554577 & $67 / 62$ & $63 / 63$ \\
\hline Turnip yellow mosaic virus (TYMV) & J04373 & $61 / 64$ & $65 / 63$ \\
\hline Erysimum latent virus (ErLV) & AF098523 & $65 / 69$ & $67 / 68$ \\
\hline Kennedya yellow mosaic virus (KYMV) & D00637 & $66 / 61$ & $63 / 61$ \\
\hline Dulcamara mottle virus (DuMV) & AY987137 & $67 / 71$ & $68 / 71$ \\
\hline Plantago mottle virus (PIMoV) & AY751779 & $67 / 64$ & $61 / 63$ \\
\hline Ononis yellow mosaic virus (OYMV) & J04375 & $69 / 60$ & $64 / 59$ \\
\hline Isolado TyToRS08 & - & - & $81 / 96$ \\
\hline Isolado VNBT & - & $81 / 96$ & - \\
\hline
\end{tabular}

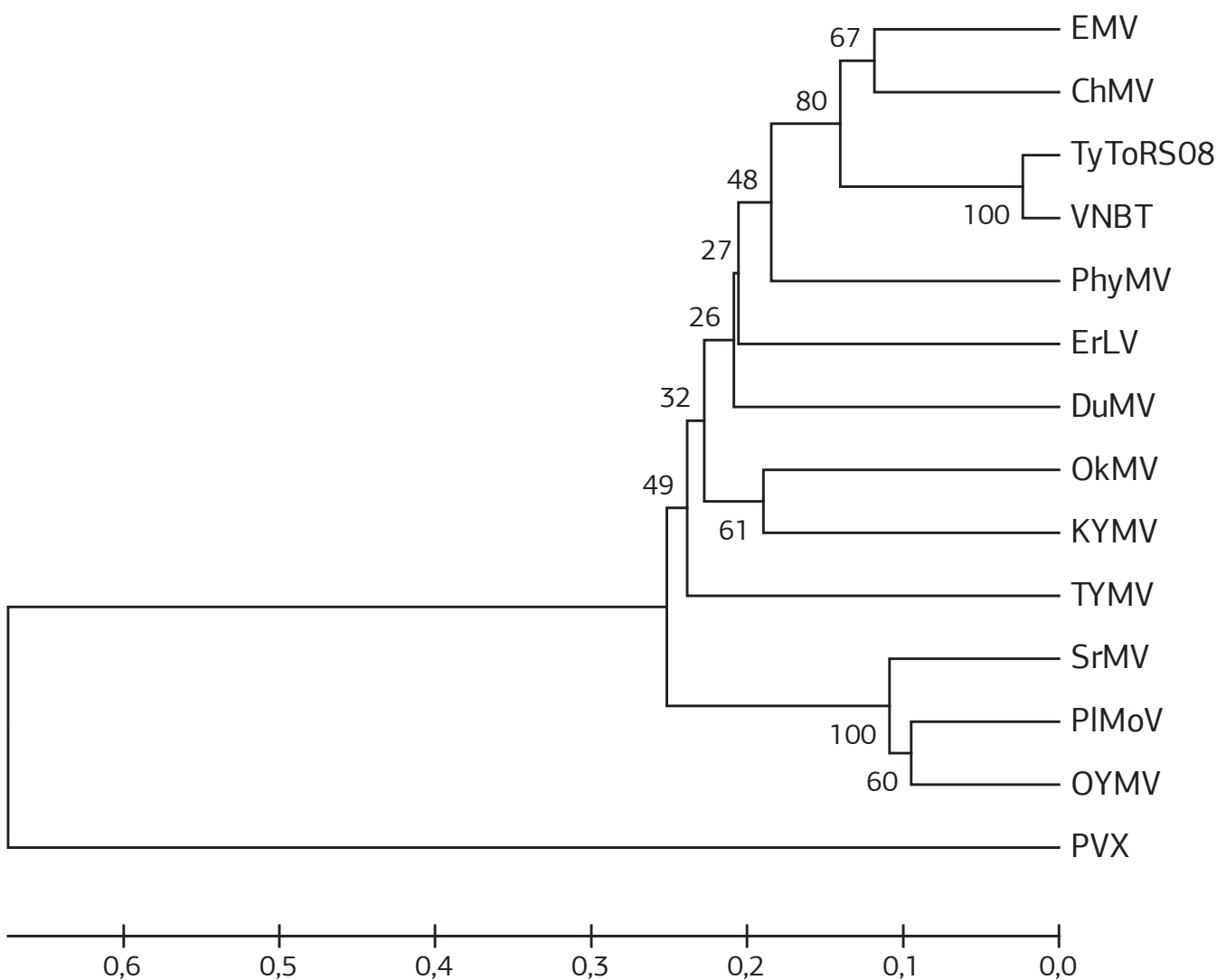

Figura 3. Árvore filogenética baseada no alinhamento múltiplo das sequências de amino ácidos dos motivos III e IV da metiltransferase e helicase, de espécies de Tymovirus, usando o método UPGMA: Eggplant mosaic virus, EMV (J04374), Chayote mosaic virus, ChMV (AF195000), Physalis mottle virus, PhyMV (Y16104), Scrophularia mottle virus, SrMV (AY751777), Okra mosaic virus, OkMV (EF554577), Turnip yellow mosaic virus, TYMV (J04373), Erysimum latent virus, ErLV, (AF098523), Kennedya yellow mosaic virus, KYMV (D00637), Dulcamara mottle virus, DuMV (AY987137), Plantago mottle virus, PIMoV (AY751779), Ononis yellow mosaic virus, OYMV (J04375). Os valores de bootstrap para mil replicações estão indicados nos ramos. A escala indica o número de substituiçôes por resíduo. O Potato virus X, PVX (EU571480), espécie tipo do gênero Potexvirus, foi empregado como grupo externo. 
tegumento envoltório da semente, uma vez que o vírus também foi detectado em sementes após a desinfecção com hipoclorito de sódio a 4\%. Porém, não se transmite de forma embrionária, pois o vírus não foi detectado nas plântulas germinadas a partir de sementes infectadas. $\mathrm{O}$ isolado TyToRS08 pode ser considerado mais um Tymovirus com potencial de disseminação por semente, assim como os isolados de Tymovirus Andean potato latent virus (APLV) e o Dulcamara mottle virus (DuMV) estudados por GiBBs et al. (1966). Tais isolados foram detectados nas sementes, mas não em plântulas, sendo diferente do TYMV que, segundo Assis Filho e Sherwood (2000), é transmitido por sementes de forma embrionária.

As sequências obtidas dos motivos III e IV da metiltransferase e helicase originaram fragmentos de DNA com aproximadamente $700 \mathrm{pb}$ as quais, quando comparadas com outras sequências de Tymovirus no GenBank, observaram-se valores de identidade de nucleotídeos da helicase que variaram de 60 a 76\%. Na comparação entre os isolados Ty ToRS08 e VNBT a similaridade chegou a $81 \%$, se do estes isolados possivelmente da mesma espécie. Porém na comparação com o EMV a similaridade foi de 68 para o TyToRS08 e de 70\% para o VNBT (Tabela 5). Os isolados TyToRS08 e VNBT não puderam ser amplificados via RT-PCR com os oligonucleotídeos específicos para a CP de isolados de EMV. Ao contrário, o isolado de EMV-PEP foi amplificado com sucesso quando se utilizaram esses oligonucleotídeos (dados não apresentados). Este resultado reforça a tese desses isolados serem, provavelmente, pertencentes a uma nova espécie de Tymovirus.

$\mathrm{Na}$ árvore filogenética (Figura 3), TyToRS08 e o VNBT agruparam-se em um único ramo, compartilhando um ancestral comum com elevado valor de bootstrap. Uma nova espécie de Tymovirus, de acordo com critérios moleculares, deverá ter a identidade de sequência da proteína capsidial menor do que $90 \%$. Além disso, a especificidade sorológica, as hospedeiras diferenciadoras e o tipo de transmissão deverão ser considerados (HAENNi e Drener, 2008). Pelos resultados observados e pelas análises filogenéticas, porém, pode-se dizer que TyToRS08 e VNBT pertencem, possivelmente, à mesma espécie, entretanto não é possível afirmar se esses dois isolados podem ser classificados como novas espécies no gênero Tymovirus.

\section{CONCLUSÃO}

O isolado TyToRS08 é uma espécie do gênero Tymovirus, família Tymoviridae, possivelmente uma nova espécie, distinta do EMV, com características biológicas de causar sintomas de manchas brancas nos frutos e necrose em sementes de tomate e ser transmitido pelas sementes de forma não embrionária, uma vez que o vírus não foi detectado nas plântulas germinadas a partir destas sementes.

\section{AGRADECIMENTOS}

Ao Conselho Nacional de Desenvolvimento Científico e Tecnológico $(\mathrm{CNPq})$, pelo auxílio financeiro concedido como bolsa de mestrado. À Mestre Silvia Regina Galetti, pelas micrografias da preparação purificada do vírus. À Pesquisadora Científica Dr. ${ }^{a}$ Eliana Rivas, pelo auxílio na identificação molecular do vírus. Ao Biólogo Deusdete Alves Pereira, da Estação Experimental Hortec (EEH), pelo apoio logístico na realização da parte experimental de campo deste trabalho.

\section{REFERÊNCIAS}

ALEXANDRE, M.A.V.; DUARTE, L.M.L; RIVAS, E.B; CHAGAS, C.M.; BARRADAS, M.M.; KOENIG, R. Petunia vein baning virus: characterization of a new Tymovirus from Petunia $x$ hybrida. Plant Disease, v.84, p.739-742, 2000.

ASSIS FILHO, M.F; SHERWOOD, L.J. Evolution of seed transmission of Turnip yellow mosaic virus and Tobacco mosaic virus in Arabidopsis thaliana. Virology, v.90, p.1233-1238, 2000.

BLANCARD, D. Enfermidades del tomate. Paris: Editora MundiPrensa/INRA, 1996.

BARRADAS, M.M; COLARICCIO, A. Inclusôes citoplasmáticas em plantas de Datura stramonium inoculadas com diferentes isolados do vírus do mosaico da berinjela (Tymovírus). Arquivos do Instituto Biológico, v.53, p.75-79, 1986

CHAGAS, C.M., VICENTE, M.; JULY, J.R. Morfologia e características de um vírus causando necrose branca em tomateiro. Arquivos do Instituto Biológico, v.42, p.157-162, 1975.

CHOMCZYNSKI, P.; SACCHI, N. Single-step method of RNA isolation by acid guanidinium thiocyanate-phenol-chloroform extraction. Analytical Biochemistry, v.162, p.156-159, 1987.

COLARICCIO, A. O impacto das viroses na cultura do tomateiro, 2004. Disponível em: http://www.feagri.unicamp.br/tomates/pdfs/ impacviros.pdf.

COLARICCIO, A.; LIMA, F.A.; EIRAS M.; CHAVES, A.L.R; LOMBARDI, R.; GALETTI, S.R.; CHAGAS, C.M; PEIXOTO, A. Detecção do Eggplant mosaic virus em plantaçóes de tomateiro no Rio Grande do Sul, Brasil. Summa Phythopathologica. v.34, supl., p.80, 2008.

CRESTANI, O.A.; KITAJIMA, E.W.; LIN, M.T. Passion fruit yellow mosaic: a new tymovirus. Phytopathology, v.76, p.951-955, 1986.

DREHER, T.W.; EDWARDS, M.C.; GIBBS, A.J.; HAENNI, A.L.; HAMMOND, R.W.; JUPIN, I.; KOENIG, R.; SABANADZOVIC, S.; MARTELLI, G.P. Family Tymoviridae. In: FAUQUET, C.M.; MAYO, M.A.; MANILOFF,J.; DESSELBERGER, U.; BALL, L.A. (Ed.). Virus taxonomy. Classification and nomenclature of viruses. Eighth report of the International Committee on Taxonomy of Viruses. San Diego: Elsevier, 2005. p.1067-1076. 
GRACIA, O.; KOENIG, R.; FELDMAN, J.M; BARRADAS, M.M. A strain of Eggplant mosaic virus causing a severe disease of tomato in Argentina. Journal of Phytopathology, v.121, p.337-345, 1998.

GIBBS, A.J; EVA, H.P.; WOODS, R.D. Some Properties of three related viruses: Andean potato latent, Dulcamara Mottle, and Onion yellow mosaic. Journal of General Microbiology, v.44, p.177-193, 1966.

GIBBS, A.J.; HARRISON, B. Eggplant mosaic virus. In: In: C.M.I./AA.B. Descriptions of Plant Viruses, Wales, n.124.

HAENNI, A.L.; DREHER, T.W. Tymoviruses. In: MAHY, B.W.J.; VAN REGENMORTEL, M.H.V. (Ed.). Encyclopedia of Virology, v.5. San Diego, CA: Academic Press, 2008. p.199-207.

INSTITUTO BRASILEIRO DE GEOGRAFIA E ESTATÍSTICA (IBGE). Levantamento sistemático da produção agrícola. v.23, p.1-80, 2010.

KITAJIMA, E.W. A rapid method to detect particles of some spherical plant viruses in fresh preparations. Journal of Electron Microscopy, v.14, p.119-121, 1968.

KUROZAWA, C.; PAVAN, M.A. Doenças do tomateiro. In: KIMATI, H.; AMORIM, L.; BERGAMIM FILHO, A.; CAMARGO, L.E.A.; REZENDE, J.A.M. (Ed.). Manual de Fitopatologia: Doenças das Plantas Cultivadas. 3.ed. São Paulo: Agronômica Ceres, 1997. v.2, p.690-719.

MARTELLI, G.P.; SABANADZOVIC, S.; ABOU-GHANEM SABANADZOVIC, N.; EDWARDS, M.C.; DREHER,T. The family Tymoviridae. Archives of Virology, v.147, p.1837-46, 2002.
MEHrotra, R.S.; AGGARWAL, A. Plant Pathology. Delhi: Tata McGraw-Hill, 2003. 846p.

PAGÁN, I.; BETANCOURT, M.; PINERO, D.; FRAILE, A.; GARCI-ARENAL, F. Genomic and biological characterization of Chiltepín yellow mosaic virus, a new tymovirus infecting Capsicum annuum var. aviculare in Mexico. Archives of Virology, v.155, p.675-684, 2010.

RIBEIRO, S.G.; KITAJIMA, E.W; OLIVEIRA, C.R.B.; KOENING, R. A strain of Eggplant mosaic virus isolated from naturally infected Tobacco plants in Brasil. Plant Disease, v.80, p.446-449, 1996.

RIVAS, B.E.; KOENNIG, R.; DUARTE, M.L.L.; ALEXANDRE, V.M. A.; GALETTI, R.S. Identification of Eggplant mosaic virus isolated from Peperomia obtusifolia. Summa Phytopathologica, v.29, p.313-316, 2003.

SABANADZOVIC, S.; GHANEM, A.N.; CASTELLANO, A.M.; DIGIARO, M.; MARTELLI, G.P. Grapevine fleck virus-like viruses in Vitis. Archives of Virology, v.145, p.553-565, 2000.

SARAIVA, M.C.A.; PAIVA, O.W.; RABELO, F.A.C.F. Transmissão por mãos contaminadas e ausência de transmissão embrionária do "Vírus do Amarelo Letal do Mamoeiro". Fitopatologia Brasileira, v.31, p.79-83, 2006.

SWOFFORD, D.L. PAUP*: Phylogenetic analysis using parsimony (*and related methods). Version 4.0b10. Sinauer Associates, Massachusetts, USA. 2002.

TAMURA, K.; DUDLEY, J.; NEI, M.; KUMAR, S. MEGA 4: Molecular Evolutionary Genetics Analysis (MEGA) software version 4.0. Molecular Biology and Evolution, v.24, p.1596-1599, 2007. 